\title{
RELATIONSHIP BETWEEN THE SUSTAINABLE DEVELOPMENT GOALS FRAMEWORK AND EMERGY EVALUATION FOR AN ENVIRONMENTAL ASSESSMENT OF THE 2030 AGENDA
}

\author{
MASSIMO GIGLIOTTI $^{1}$, VALENTINA NICCOLUCCI ${ }^{1}$, MICHELA MARCHI ${ }^{1}$, \\ FRANCESCA GAGLIARDI ${ }^{2}$ \& FEDERICO MARIA PULSELLI $^{1}$ \\ ${ }^{1}$ Ecodynamics Group, Department of Physical, Earth and Environmental Sciences, University of Siena, Italy \\ ${ }^{2}$ Department of Economics and Statistics, University of Siena, Italy
}

\begin{abstract}
The United Nations (UN) Agenda 2030 represents the set of strategies for sustainable development approved by the UN in September 2015, divided into a framework of 17 Sustainable Development Goals (SDGs). All countries are called to plan a national strategy to achieve these interconnected goals. Their achievement will lead the world towards a new path of development and cooperation. For this reason, the Agenda is characterized by three fundamental concepts: universality, integration and transformation. These three features are also the conceptual basis of the environmental accounting method based on emergy (spelled with an "m"), a methodology able to represent the energetics of a process or a system, using solar energy as a common denominator. Some analyses between 2016 and the present day have reported how the UN Agenda 2030 is still too anthropocentric, giving ample space to the socio-economic pillar of sustainability, to the disadvantage of the environmental system. As the UN Agenda 2030 tends to focus on the socio-economic aspects of human life, this study will assess how much attention is paid to the environmental issues by considering the relationship between the SDG Index and emergy evaluation for 155 countries. Our quali-quantitative approach shows that emergy can give a relevant contribution to the SDG framework, especially in the environmental sphere.
\end{abstract}

Keywords: UN, sustainability, indicators, environmental accounting, resources.

\section{INTRODUCTION}

In September 2015, the 193 member states of the United Nations (UN) approved a framework of 17 strategic objectives that had to be universal and inclusive for all social classes and levels of development. These objectives are known as Sustainable Development Goals (SDGs), also known as Global Goals, and represent the UN's 2030 agenda.

The SDGs encompass environmental sustainability, social inclusion and economic development, representing the three pillars of sustainability [1]. These characteristics are joined by the need to work in a climate of peace, strong institutions and international partnership.

The SDG proposal refers to strong conceptual pillars that characterize the essence of the initiative: universality, because these apply to nations, cities, companies, schools, organizations and common people that are called to act; integration, because goals and targets are all interconnected and considering one of them in isolation should be avoided; and transformation, because to achieve these goals implies deep changes in human actions [2].

All countries of the world are called to make policies to implement a sustainable development strategy in their government action in order to achieve the 17 goals by 2030. In the first period after their formalization, the key issue of the implementation of the 2030 agenda in international policies was the way in which the SDGs interact with each other [3], analysing positive and/or critical aspects. 
The Bertelsmann Stiftung and the Sustainable Development Solution Network (SDSN) publish an annual report presenting the results of an index of the countries in line with the achievement of the 17 SDGs. "The SDG Index and Dashboards describe countries' progress towards achieving the SDGs and indicate areas requiring faster progress. The global SDG Index score and scores by goal can be interpreted as the percentage of achievement" [4]. Three Scandinavian countries are at the top of the SDG Index in 2018, but no country has achieved all of the goals. Although many associations and companies show interest and commitment to achieving these goals, at the political level there is a lack of a strong position on the part of governments. Montenegro is one of the few countries whose government has adopted a strategy for the national implementation of the SDGs [5].

Many studies have highlighted critical issues between the goals and targets of the 2030 Agenda and the right balance between the three pillars of sustainability, i.e. economic, social and environmental systems. Rockström and Sukhdev [6] suggest a subdivision of the 17 goals on the three sustainability spheres, and it is clear that the SDG framework has shifted heavily on the social system, leaving out, above all, the environmental system. Interestingly, Hajer et al. [7] illustrate the relationships between the SDG proposal and the planetary boundaries framework.

Wackernagel et al. [8] presents a relationship between the Human Development Index (HDI) and the Ecological Footprint (EF). Their results are generically summarized in Fig. 1 (countries are distributed along the curve). High HDI corresponds to high EF and vice versa, which means that high development levels are supported by high resource consumption, and countries with low or very low levels of human development are also poor in resource availability and consumption. No nation is included in the so-called "global sustainable development quadrant" (g.s.d.q.), defined by the study as the area in which a good level of human development is fed by a fair and limited use of natural resources.

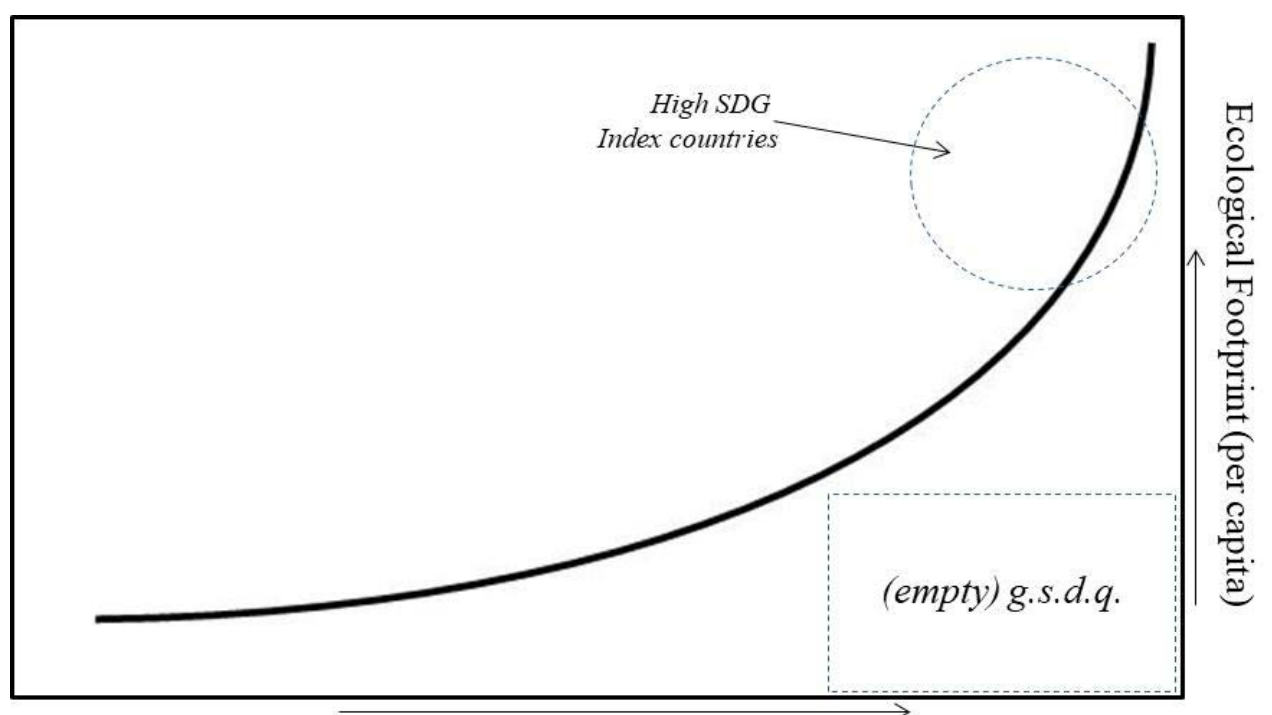

Human Development Index

Figure 1: Relationship between the Human Development Index and the Ecological Footprint. (Source: modified from Wackernagel et al. [8].) 
In their work, Wackernagel et al. [8] show how the best performances in terms of the SDG Index are those of countries with the highest EF (included in the dashed circle, Fig. 1). This highlights how the SDGs are not performing enough to evaluate the sustainability of the countries in terms of resource consumption; in other words, the SDG Index does not take into great consideration the appropriation of natural resources.

In this paper, we will explore the SDG framework using the viewpoint and theoretical foundation of the environmental accounting methodology, called emergy evaluation [9]. Emergy accounting enables us to identify and evaluate the amount and importance of all the resources (energy and material flows) feeding a system, independent of their monetary value, in a lapse of time (generally one year). We will also propose a computation to investigate the relationship between the emergy flow and the SDG Index for a wide number of countries.

\section{MATERIALS AND METHODS}

Emergy is a thermodynamics-based entity that reflects the story of energy transformations on Earth, from primary energy (namely, solar) to all the other possible forms of energy that enable everything to exist: matter and energy flows, meteorological phenomena, all kinds of resources and deposits/storages, living beings, ecosystems, cities and nations. Everything depends on energy and energy transformations from a form into another, and this dynamic determines the existence of the so-called life support system. Odum [9], starting from the idea that different forms of energy have different qualities, proposed a method to quantify the quality of energy [10] on the basis of the amount of energy of one type necessary to obtain a flow of energy of another. Going back to solar energy, as the primary energy that activates all processes in nature, he defined emergy as the amount of solar energy directly or indirectly necessary to obtain a flow of energy or a product [11]. Emergy is the basis for an environmental accounting system able to estimate the amount of resources that converge in a lapse of time (e.g. one year) to support a system - an organism, a production process, a nation - expressed in solar emergy joules per year (sej/yr). Here we collect the data for more than 150 national economies from the National Emergy Accounting Database for the year 2014 [12]. The results, expressed in terms of emergy flow per capita, show the amount of resources that are necessary in one year to support each national system.

On the other hand, the same countries are also ranked based on the SDG Index as presented in the aforementioned SDG Index Report [4].

\section{RESULTS AND DISCUSSION}

Fig. 2 presents a typical emergy diagram of a national economy [9], modified to include the informative capacity of SDGs. The emergy approach enables us to illustrate and understand the functioning of systems. One effective way to detect the energetic of systems is by the use of diagrams [9], [13]. In the case of a national system, different compartments and elements and their interactions can be visualized at the same time. Diagrams show the dynamics of a system and the use of resources from primary energy, to natural transformations, human settlements and the production of goods and services for the economy. The market is, therefore, at the end of the long and slow process that makes resources supporting human actions available.

In Fig. 2, the 17 SDGs are placed in the diagram next to flows, elements or compartments that seem suitable to represent the essence of each of them. We accept a certain level of arbitrariness in the construction of the overall picture, as well as the fact that the range of each SDG is wider than what is represented here. However, what is also clear is that the SDG framework tends to encompass more social and economic issues (right side of Fig. 2) than purely environmental ones. 


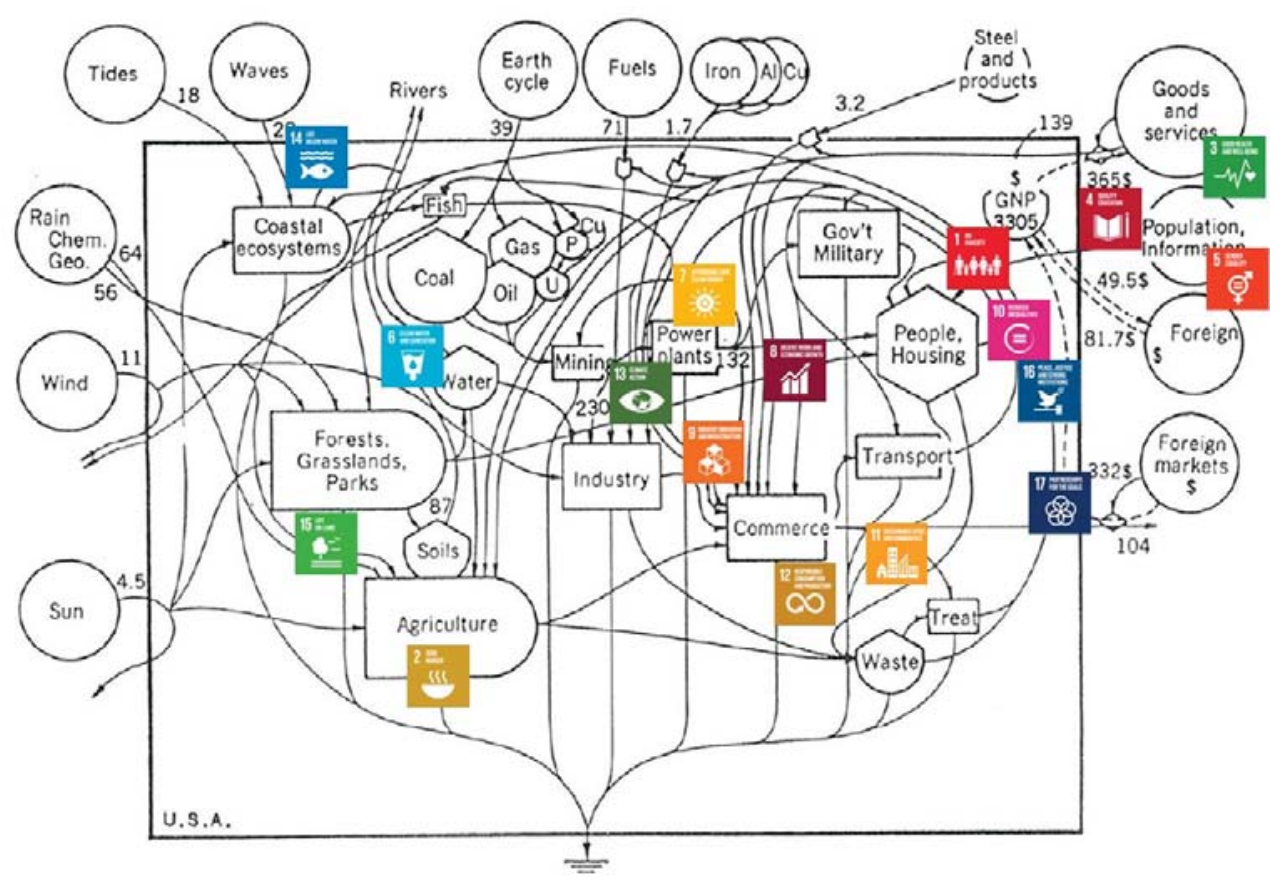

Figure 2: Emergy diagram for the USA and the position of the 17 SDGs.

To strengthen this observation, we computed emergy per capita and the SDG Index for 155 countries. These values have been distributed on a Cartesian plane following the two variables, simulating the study by Wackernagel et al. [8]. In Fig. 3, the distribution of countries in the graph is shown. Not surprisingly, our results confirm what Wackernagel et al. [8] argued: that the best performances in terms of the SDG Index are those of countries that consume a great amount of environmental resources. In fact, the distribution is linear and is characterized by coupling high emergy and high SDGs Index values, and vice versa.

A so-called sustainability box has been identified in the Fig. 3, determined by the fourth quartile of the SDG Index and the first quartile of the emergy per capita (i.e. the highest level of SDG Index and the lowest level of emergy per capita). This box indicates the countries that achieve a good level of SDG Index without exploiting a large amount of resources. It is evident that no country is in the sustainability quadrant. The closest country to the sustainability region is Cuba.

Despite outliers such as Luxembourg and the Slovak Republic who have the highest emergy values but lie within the first quartile of the SDG Index, or Bangladesh and Iran who have the lowest emergy values, the most distant countries from a sustainability threshold are Swatziland and Djibuti, which lie within the fourth quartile of both variables.

Regardless of the specific position of each country, from this analysis it emerges that to have a complete view of the sustainability of the world, the SDG framework should be integrated by complementary information like that coming from the application of pure ecological indicators (such as emergy and EF). In our opinion, this is not a problem, but we must be aware that the social and economic component of our life must be physically 


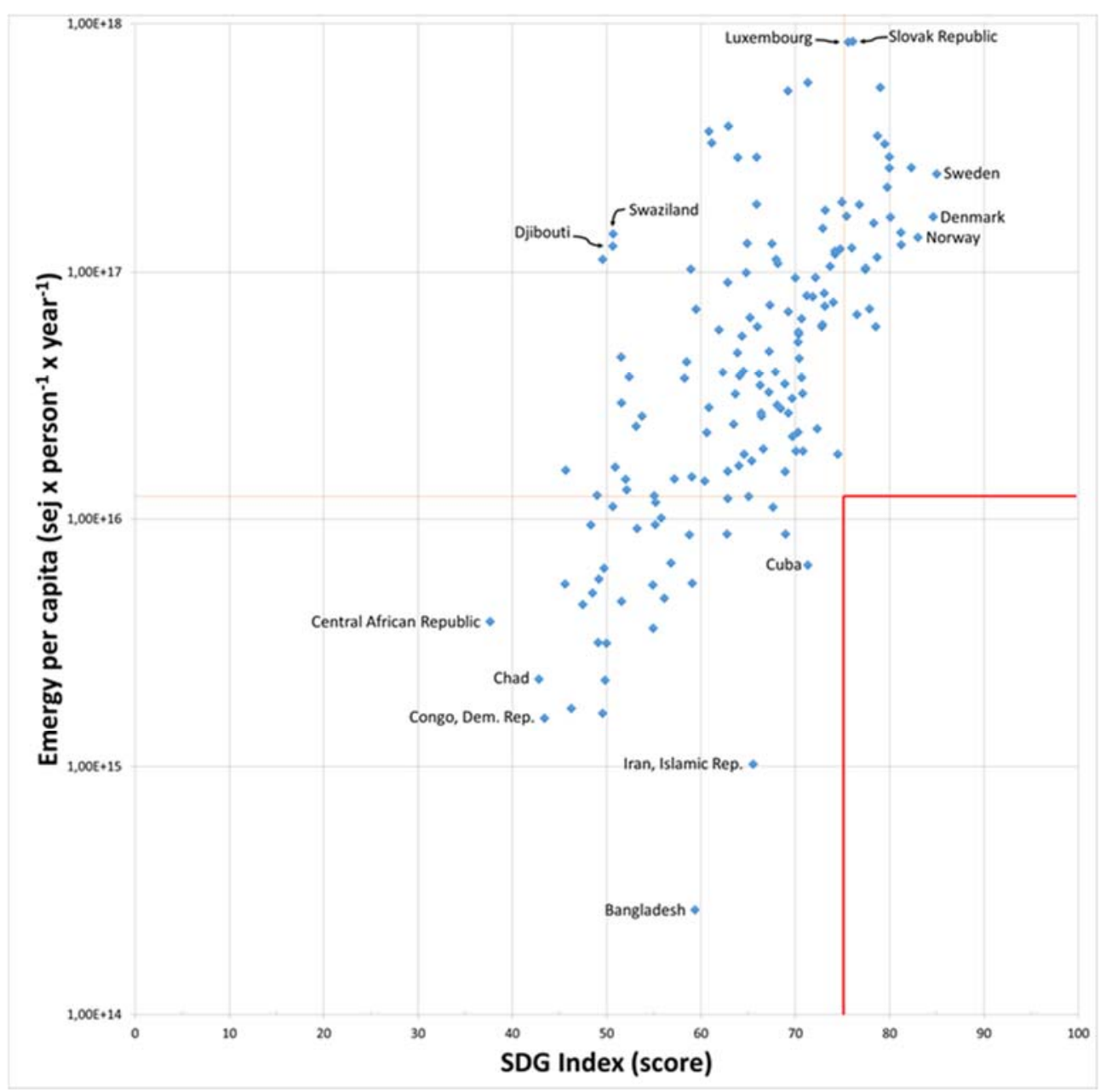

Figure 3: Relationship of SDG Index and emergy flow at the country level.

supported by the environment and natural resources and processes [1]. As a consequence, the spectrum of information needed to adopt good sustainability policies, both worldwide and in every single country, must be widened by expanding, first of all, the awareness of the existence of nature and ecosystem services. In other words, we can argue that the configuration of the SDGs within the emergy diagram, as shown in Fig. 2, is potentially one of the reasons why the sustainability box in Fig. 3 is empty.

\section{CONCLUSIONS}

This study confirms and strengthens the conclusion proposed by Wackernagel et al. [8], who state that "if we want to have a future, SDGs need to robustly embrace the reality of resource constraints and climate change. Also, we need robust accounting tools that track the outcomes". In this sense, emergy accounting is a "robust" systematic and self-consistent method able to stimulate the knowledge of, and interest in, ecosystems and natural resources. To connect emergy to the SDG framework, we can recall the three pillars mentioned 
previously: universality, integration and transformation. Regards universality, emergy is an encompassing method for investigating the network of connections, from primary energy to more complicated structures, ecosystems, societies and information (different systems); regards integration, emergy focuses on the flows of energy and matter that connect the elements of a system, which is important for detecting different behavioural aspects (different goals); and regards transformation, emergy, by definition, is the ideal method for representing energy transformations and changes in natural and human systems.

\section{REFERENCES}

[1] Pulselli, F.M., Coscieme, L., Neri, L., Regoli, A., Sutton, P., Lemmi, A. \& Bastianoni, S., The world economy in a cube: A more rational structural representation of Sustainability. Global Environmental Change, 35, pp. 41-51, 2015.

[2] United Nations (UN), Global sustainable development report 2015. Division for Sustainable Development, Department of Economic and Social Affairs: New York, 2015.

[3] Weitz, N., Carlsen, H., Nilsson, M. \& Skånberg, K., Towards systemic and contextual priority setting for implementing the 2030 Agenda. Sustainability Science, 13, pp. 531-548, 2018.

[4] Bertelsmann Stiftung \& Sustainable Development Solutions Network, SDG index and dashboard report 2018 - global responsibilities implementing the goals. http://www.sdgindex.org/assets/files/2018/01\%20SDGS\%20GLOBAL\%20EDITIO N\%20WEB\%20V9\%20180718.pdf, 2018.

[5] Galli, A., Đurović, G., Hanscom, L. \& Knežević, J., Think globally, act locally: Implementing the sustainable development goals in Montenegro. Environmental Science \& Policy, 84, pp. 159-169, 2018.

[6] Rockström, J. \& Sukhdev, P., How food connects all the SDGs. The Stockholm Resilience Centre. Document, http://www.stockholmresilience.org/research/researchnews/2016-06-14-how-food-connects-all-the-sdgs.html.

[7] Hajer, M., Nilsson, M., Raworth, K., Bakker, P., Berkhout, F., de Boer, Y., Rockström, J., Ludwig, K. \& Kok, M., Beyond cockpit-ism: Four insights to enhance the transformative potential of the Sustainable Development Goals. Sustainability, 7, pp. 1651-1660, 2015.

[8] Wackernagel, M., Hanscom, L. \& Lin, D., Making the sustainable development goals consistent with sustainability. Frontiers in Energy Research, 5, p. 18, 2017.

[9] Odum, H.T., Environmental Accounting: Emergy and Environmental Decision Making, Chichester Wiley: New York, 1996.

[10] Brown, M. \& Ulgiati, S., Energy quality, emergy, and transformity: H.T. Odum's contributions to quantifying and understanding systems. Ecological Modelling, 178, pp. 201-213, 2004.

[11] Odum, H.T., Emergy of Global Processes: Folio \#2, Handbook of Emergy Evaluation, Center for Environmental Policy, University of Florida: Gainesville, FL, 2000.

[12] National Environmental Accounting Database V2.0, https://www.emergy-nead.com/ home, 2018.

[13] Brown, M.T., A picture is worth a thousand words: Energy systems language and simulation. Ecological Modelling, 178, pp. 83-100, 2004. 